\title{
Healthcare and health promotion for the sub-health state Hong Kong population
}

Hong Kong Med J 2021;27:73

https://doi.org/10.12809/hkmj198370

To the Editor-We have previously reviewed a number of issues and challenges associated with in-flight medical emergencies. ${ }^{1}$ Recently, during a short flight from Hong Kong to Kaohsiung, one author (KLH) encountered a male passenger who summoned the flight attendants for medicine as he was having stomach cramps. The flight attendants rightly enquired about his history of drug allergy. Both antacids and paracetamol were available but only one should be offered; the man opted to take the paracetamol, and he seemed to feel better within a few minutes of taking it.

The man claimed that his stomach pain was triggered by eating and he was fine when emptystomached. He denied any consumption of alcohol, tobacco, or over-the-counter medications. $\mathrm{He}$ claimed that the pain recurred approximately every month, but he had not seen any doctor about it. The author took this opportunity to provide health promotion education, noting the possibility of peptic ulcer disease and helicobacter infection, and recommending him to consult a doctor to follow up on the issue. The male passenger and his female companion appeared to be mistrustful at first but were at the end grateful for the health advice provided.

This episode exposed one of the fundamental health issues among Hong Kong citizens: living in a 'sub-health' state without seeking medical advice. ${ }^{2}$ This phenomenon is often due to people having a fear of doctors, antibiotics, steroids, or Western medicine. ${ }^{3,4}$ A sub-health state is characterised by some disturbances in psychological behaviours or physical characteristics, or in some indices of medical examination, with no typical pathologic features. ${ }^{5} \mathrm{~A}$ survey conducted by The University of Hong Kong in 2013 revealed that $97 \%$ of the surveyed Hong Kong citizens have experienced at least one sub-health symptom, and the most affected were aged 30 to 49 years, with an average of more than nine symptoms each. ${ }^{2}$ The impact should not be underestimated as $64 \%$ of the respondents reported that their daily lives were adversely affected. ${ }^{2}$

Public health promotion should target this sub-health state population, to prevent the potential development of chronic diseases. Health authorities should consider validated questionnaires to measure sub-health status in the primary care setting, so that interventions can be provided before it is too late. ${ }^{6}$

\section{Author contributions}

The authors had full access to the data, contributed to the letter, approved the final version for publication, and take responsibility for its accuracy and integrity.

\section{Conflicts of interest}

As an editor of the journal, KL Hon was excluded from the review process for this letter. The other author has disclosed no conflicts of interest.

KL Hon *, MB, BS, MD

Karen KY Leung, MB, BS, MRCPCH

Department of Paediatrics and Adolescent Medicine, The Hong Kong Children's Hospital, Hong Kong

*Corresponding author: ehon@hotmail.com

\section{References}

1. Hon KL, Leung KK. Review of issues and challenges of practicing emergency medicine above 30,000-feet altitude: 2 anonymized cases. Air Med J 2017;36:67-70.

2. Public Opinion Programme, The University of Hong Kong. Survey on Hong Kong Citizens' knowledge and opinions on sub-health. 2013. Available from: https://www.hkupop. hku.hk/english/report/subhealth/index.html. Accessed 24 Dec 2019.

3. Chen J, Xiang H, Jiang P, et al. The role of healthy lifestyle in the implementation of regressing suboptimal health status among college students in China: A nested case-control study. Int J Environ Res Public Health 2017;14. pii: E240.

4. Wu S, Xuan Z, Li F, et al. Work-recreation balance, healthpromoting lifestyles and suboptimal health status in southern china: a cross-sectional study. Int J Environ Res Public Health 2016;13. pii: E339.

5. Li G, Xie F, Yan S, et al. Subhealth: definition, criteria for diagnosis and potential prevalence in the central region of China. BMC Public Health 2013;13:446.

6. Yan YX, Liu YQ, Li M, et al. Development and evaluation of a questionnaire for measuring suboptimal health status in urban Chinese. J Epidemiol 2009;19:333-41. 